\title{
In vivo Production of a Tissue-destructive Protease by Legionella pneumophila in the Lungs of Experimentally Infected Guinea-pigs
}

\author{
By J. W. CONLAN, ${ }^{*}$ A. WILliams And L. A. E. ASHWORTH \\ Experimental Pathology Laboratory, PHLS Centre for Applied Microbiology and Research, \\ Porton Down, Salisbury, Wiltshire SP4 OJG, UK
}

(Received 15 July 1987; revised 17 August 1987)

A tissue-destructive protease of Legionella pneumophila was assayed for in the lungs of experimentally infected guinea-pigs by ELISA. It was found in amounts equivalent to the known lethal dose of purified protease administered by the intranasal route. The identity of the protease was confirmed by immunoblot analysis. This is further evidence that Legionella pneumophila protease may play a major role in the pathogenesis of Legionnaires' disease.

\section{INTRODUCTION}

Many extracellular proteolytic activities have been described for Legionella pneumophila (Müller, 1980, 1981; Thompson et al., 1981 ; Berdal et al., 1982; Gul'nik et al., 1986). Recently six discrete extracellular proteases were isolated from L. pneumophila (Conlan et al., 1986). When administered into the lungs of guinea-pigs, one protease with in vitro activity against collagen, casein and gelatin [tissue-destructive protease (TDP)] elicited pulmonary lesions which were pathologically similar to those observed in clinical and experimental Legionnaires' disease (Baskerville et al., 1986; Conlan et al., 1986). The present investigation was undertaken to demonstrate in vivo production of TDP in the lungs of guinea-pigs challenged with a lethal, infectious aerosol of $L$. pneumophila.

\section{METHODS}

Organisms. L. pneumophila strain Corby is a serogroup 1 human isolate (kindly provided by Dr R. A. Swann, John Radcliffe Hospital, Oxford, UK). It had been passaged four times on charcoal yeast extract (CYE) agar (Edelstein, 1981) before use in the present study.

Purification of TDP and LPS (serogroup 1). This was done as described by Conlan \& Ashworth (1986) and Conlan et al. (1986).

TDP production in vitro. Stock cultures of strain Corby, stored at $-70^{\circ} \mathrm{C}$, were thawed and used to inoculate starter cultures in $100 \mathrm{ml}$ yeast extract broth (YEB; Ristroph et al., 1980) in $500 \mathrm{ml}$ conical flasks, incubated aerobically at $37^{\circ} \mathrm{C}$ for $24 \mathrm{~h}$ on an orbital shaker (100 r.p.m.). Purity was checked by Gram's stain and by the ability of the organism to grow on CYE agar but not on blood agar (incubated aerobically at $37^{\circ} \mathrm{C}$ for $3 \mathrm{~d}$ ). Cultures for enzyme production ( $500 \mathrm{ml}$ YEB in 21 flasks) were inoculated with $5 \mathrm{ml}$ of starter culture and incubated as above. At various times samples were removed and, following dilution in sterile distilled water, total counts (using a Helber slide) and viable counts were done. CYE agar was used for viable counts. Samples (10 ml) were then centrifuged $(2000 \mathrm{~g}$ for $30 \mathrm{~min}$ ). In preliminary studies supernatant fractions from the centrifugation step were sterilized by membrane filtration $(0.22 \mu \mathrm{m})$ to remove particulate debris. This was accompanied by a marked decrease in recoverable TDP due to binding to the filter. Therefore, to remove particulate matter supernatant fractions from the low speed centrifugation were recentrifuged (10000 for $10 \mathrm{~min})$. Supernatant fractions from the second centrifugation were assayed for TDP by casein precipitation and by enzyme-linked immunosorbent assay (ELISA).

\footnotetext{
Abbreviations: c.p.u., casein precipitating unit; HRP, horse-radish peroxidase; TDP, tissue-destructive protease; CYE agar, charcoal yeast extract agar; YEB, yeast extract broth.
} 
Cell pellets from the first centrifugation (i.e. from $10 \mathrm{ml}$ YEB culture) were washed once by resuspension in cold PBS $\left(8 \mathrm{~g} \mathrm{NaCl}, 0.2 \mathrm{~g} \mathrm{KCl}, 1 \cdot 15 \mathrm{~g} \mathrm{Na}_{2} \mathrm{HPO}_{4}, 0.2 \mathrm{~g} \mathrm{KH}_{2} \mathrm{PO}_{4} \mathrm{l}^{-1}\right.$ ), followed by centrifugation ( $2000 \mathrm{~g}$ for $30 \mathrm{~min}$ ) and resuspension in $10 \mathrm{ml}$ cold PBS. Cells were sonicated (MSE Soniprep 150, at maximum amplitude; $6 \times 30 \mathrm{~s}$ pulses) on ice. Following sonication the suspensions were centrifuged $(2000 \mathrm{~g}, 30 \mathrm{~min})$ and supernatant fractions assayed for TDP as above. TDP of known activity, sonicated as for cells, was included as a control.

TDP production in vivo. L. pneumophila was grown on CYE agar for $3 \mathrm{~d}$ (aerobically, $37^{\circ} \mathrm{C}$ ) and harvested by suspension in sterile distilled water. Fourteen female Dunkin Hartley guinea-pigs were infected with a small particle aerosol of L. pneumophila (retained dose $40 \mathrm{LD}_{50}$ ) as described by Baskerville et al. (1981). Animals were killed by sodium pentobarbitone anaesthesia at daily intervals. Their lungs were removed whole and stored at $-20{ }^{\circ} \mathrm{C}$ until termination of the experiment (maximum storage period was $3 \mathrm{~d}$ ). Thawed lungs were suspended in $10 \mathrm{ml}$ sterile distilled water and macerated for $2 \mathrm{~min}$ in a MSE homogenizer. Dilutions of macerates were plated out on CYE agar for viable counts. Supernatant fractions of centrifuged macerates $(10000 \mathrm{~g}$ for $10 \mathrm{~min})$ were assayed for TDP by ELISA. The large quantities of endogenous proteolytic activity present in the macerates precluded the biochemical determination of specific L. pneumophila TDP.

Enzyme assay. TDP enzyme activity in vitro was detected using casein incorporated into agar [1\%,w $/ \mathrm{v}$, sodium caseinate (Difco), 1\%, w/v, agar, 0.001\%,w/v, sodium azide in $50 \mathrm{~mm}$-sodium phosphate buffer, $\mathrm{pH} 6.2]$ as substrate. Molten casein-agar was poured into $12 \mathrm{~cm}$ Petri dishes and wells $(4 \mathrm{~mm})$ cut in the solidified medium. Test materials were serially twofold diluted in $50 \mathrm{~mm}$-sodium phosphate buffer, $\mathrm{pH} 7 \cdot 0$, and $50 \mu \mathrm{l}$ transferred into the wells of the casein-agar plate. One unit of enzyme activity [casein precipitating unit (c.p.u.)] was defined as the amount of enzyme required to yield the smallest detectable radial zone of casein precipitate. The assay detected as little as $20 \mathrm{ng}$ of active TDP.

Antisera and conjugates. Antibodies against TDP were raised as follows. New Zealand White rabbits were bled before inoculation of $90 \mu \mathrm{g}$ purified TDP (Conlan et al., 1986) in incomplete Freund's adjuvant distributed between two intramuscular and two dorsal subcutaneous sites. Rabbits were boosted with the same antigen at 3 week intervals for 12 weeks. Three weeks after the final boost these animals were exsanguinated under sodium pentobarbitone anaesthesia. The immunoglobulin $\mathrm{G}(\mathrm{IgG})$ fraction was obtained from high titre sera by Protein $\mathrm{A}$ affinity chromatography. Antiserum was dialysed against $0 \cdot 14 \mathrm{M}$-sodium phosphate buffer, $\mathrm{pH} 8 \cdot 0$, and $3 \mathrm{ml}$ vols were circulated several times through a $10 \times 50 \mathrm{~mm}$ column of Sepharose Protein A (Pharmacia) equilibrated with the same buffer. The gel bed was washed with 3 bed vols of this buffer followed by successive washes with $0 \cdot 1 \mathrm{M}$ trisodium citrate/citric acid buffer, pH 6.0 and 3.0, respectively. Anti-TDP IgG was recovered in the pH 3.0 wash and was immediately dialysed against PBS (see above). The anti-TDP IgG (10 mg) was conjugated to $10 \mathrm{mg}$ of horse-radish peroxidase (HRP; Sigma type IV) by the method of Nakane \& Kawaoi (1974).

Antiserum to $L$. pneumophila LPS was prepared as described by Conlan \& Ashworth (1986).

ELISA for TDP. YEB and lung-macerate supernatant fractions were titrated by a sandwich ELISA in 96 well microtitre plates (Nunc Immunoplate 1) at $18-22{ }^{\circ} \mathrm{C}$ with $100 \mu \mathrm{l}$ vols of the various reagents per well. PBS, containing $0 \cdot 1 \%(\mathrm{v} / \mathrm{v})$ Tween 20 to block non-specific binding of the reagents to the wells, was used as wash solution. Wash solution containing $10 \%(\mathrm{v} / \mathrm{v})$ new-born calf serum was used as diluent. Plates were washed by filling and emptying wells three times using a semi-automatic washer (Ilacon). Wells were coated overnight with anti-TDP IgG $\left(2 \mu \mathrm{g} \mathrm{ml}^{-1}\right)$ in $50 \mathrm{~mm}$-sodium carbonate/sodium hydrogen carbonate buffer, $\mathrm{pH} 9 \cdot 5$, then washed. Serial twofold dilutions of test materials were made in a second plate and $100 \mu \mathrm{l}$ transferred from each well to the corresponding well on the washed, coated plate which was then incubated for $2 \mathrm{~h}$ with shaking. The plate was

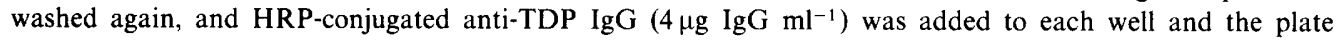
incubated for a further $2 \mathrm{~h}$ with shaking. After washing the plate to remove unbound conjugate, substrate was added and after a further 20 min incubation the absorbance was measured using a Titretek Multiskan photometer fitted with a $450 \mathrm{~nm}$ filter. The substrate was 3,3',5,5'-tetramethylbenzidine. This was dissolved in dimethylsulphoxide and diluted to $0.1 \mathrm{mg} \mathrm{ml}^{-1}$ in $50 \mathrm{~mm}$-sodium acetate/acetic acid buffer, pH 6.0, with $\mathrm{H}_{2} \mathrm{O}_{2}$ added to $0.007 \%$. The reaction was stopped by addition of $25 \mu \mathrm{l}$ of $\mathrm{I} \mathrm{M}_{-}-\mathrm{H}_{2} \mathrm{SO}_{4}$. Purified TDP was included on each plate as a standard.

ELISA for LPS. This was done as above using anti-LPS IgG $\left(2 \mu \mathrm{g} \mathrm{m}^{-1}\right)$ as coating antibody. The HRP conjugate of this antibody was used at $2 \mu \mathrm{g} \mathrm{IgG} \mathrm{ml} \mathrm{m}^{-1}$. Purified $L$. pneumophila LPS was included on each plate as standard. The ELISA for both TDP and LPS could accurately measure down to $5 \mathrm{ng}$ of the respective antigens.

Effect of lung macerate and YEB on ELISA titre. Purified TDP (66 ng) and LPS (250 ng) were diluted (100 $\mu 1$ vols) in parallel in twofold series in PBS, YEB and lung-macerate supernatant and were assayed by ELISA. For each antigen, six replicate assays were done.

Immunoblot analysis. Lung-macerate supernatants were run on SDS-PAGE (12\%, w/v, separating gel) using the Laemmli (1970) buffer system. After electrophoresis gels were electroblotted onto nitrocellulose paper at $100 \mathrm{~mA}$ for $2 \mathrm{~h}$ using a semi-dry blotter (Ancos, Denmark) according to the method of Khyse-Andersen (1984). Blots were visualized using 4-chloro-1-naphthol as substrate as described by Newell (1987). 


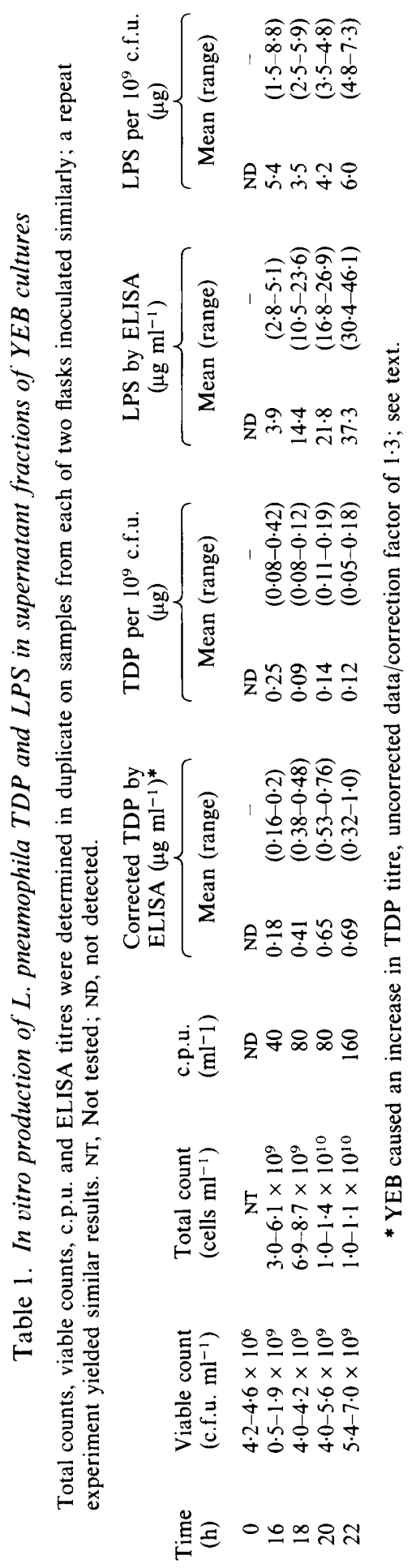


Table 2. In vivo detection of L. pneumophila TDP and LPS in the lungs of aerosol-infected guinea-pigs

Viable counts and TDP antigen were determined in duplicate for each guinea-pig. A repeat infection experiment with a different batch of cells for the $72 \mathrm{~h}$ post-infection assays yielded similar results. ND, Not detected

\begin{tabular}{|c|c|c|c|c|c|c|c|c|c|c|}
\hline \multirow{2}{*}{$\begin{array}{l}\text { Time } \\
\text { (d) }\end{array}$} & \multirow{2}{*}{$\begin{array}{c}\text { No. of } \\
\text { animals }\end{array}$} & \multirow{2}{*}{$\begin{array}{l}\text { Viable count } \\
\text { (c.f.u.)* }\end{array}$} & \multicolumn{2}{|c|}{$\begin{array}{l}\text { Corrected TDP } \\
\text { by ELISA }(\mu \mathrm{g})^{* \dagger}\end{array}$} & \multicolumn{2}{|c|}{$\begin{array}{l}\text { TDP per } 10^{9} \\
\text { c.f.u. }(\mu \mathrm{g})\end{array}$} & \multicolumn{2}{|c|}{$\begin{array}{l}\text { LPS by ELISA } \\
\qquad(\mu \mathrm{g})^{*}\end{array}$} & \multicolumn{2}{|c|}{$\begin{array}{l}\text { LPS per } 10^{9} \text { c.f.u. } \\
\qquad(\mu \mathrm{g})\end{array}$} \\
\hline & & & \multicolumn{2}{|c|}{ Mean (range) } & \multicolumn{2}{|c|}{ Mean (range) } & \multicolumn{2}{|c|}{ Mean (range) } & \multicolumn{2}{|c|}{ Mean (range) } \\
\hline 0 & 2 & $3.8-5.5 \times 10^{5} \ddagger$ & ND & - & - & - & ND & - & - & - \\
\hline 1 & 3 & $0.9-3.9 \times 10^{7}$ & ND & - & - & - & 0.94 & $(0 \cdot 65-1 \cdot 13)$ & $47 \cdot 3$ & $(28 \cdot 1-68 \cdot 0)$ \\
\hline 2 & 3 & $0.7-3.4 \times 10^{9}$ & $1 \cdot 1$ & $(0 \cdot 5-2 \cdot 3)$ & $4 \cdot 6$ & $(2 \cdot 5-6 \cdot 8)$ & $19 \cdot 2$ & $(12 \cdot 1-32 \cdot 4)$ & $112 \cdot 0$ & $(55 \cdot 9-198 \cdot 0)$ \\
\hline 3 & $4 \S$ & $1.6 .4 .9 \times 10^{9}$ & $10 \cdot 4$ & $(5 \cdot 8-22 \cdot 5)$ & $5 \cdot 2$ & $(3 \cdot 5-7 \cdot 9)$ & $336 \cdot 0$ & $(214-557)$ & $156 \cdot 0$ & $(90 \cdot 3-252 \cdot 0)$ \\
\hline
\end{tabular}

* In total lung-macerate supernatant fraction.

† Lung-macerate supernatant fraction caused an increase in TDP titre, uncorrected data/correction factor of 6.7 ; see text.

$\ddagger$ Corresponds to initial retained dose by aerosol infection equivalent to $40 \mathrm{LD}_{50}$.

$\S$ Excluding two animals that died.

\section{RESULTS}

\section{Effect of lung macerate and YEB on ELISA titre}

Lung-macerate supernatant and YEB caused a 6.7-fold (range 5.6-7.9) and 1.3-fold (range $1 \cdot 2-1 \cdot 5$ ) increase, respectively, in TDP titre compared to that for TDP diluted in PBS. The LPS titre was unaffected by the presence of either lung-macerate supernatant or YEB (data not shown).

\section{In vitro production of TDP and LPS}

The total and viable counts (Table 1) indicated that the sampling period covered late exponential phase to early stationary phase of $L$. pneumophila growth. The mean viability of $L$. pneumophila during this time was $52 \%$. This may be a reflection of plating efficiency rather than a true estimate of viability. TDP, measured enzymically (c.p.u.) and as antigen (ELISA), increased over the sample period. The two assays did not yield parallel results due to the relative insensitivity of the enzymic assay. The calculated protease levels per $10^{9}$ organisms remained relatively constant. A similar pattern was observed for LPS (Table 1).

\section{In vivo production of TDP and LPS}

TDP was not detectable until $2 \mathrm{~d}$ post-infection, then rose markedly on day three, by which time two of six remaining animals had died (Table 2). Calculated TDP levels per $10^{9}$ organisms remained constant, but were approximately 30 -fold (range 6-158-fold) higher than the levels detected in vitro (cf. Tables 1 and 2). LPS was detected on day one (Table 2) and increased 20fold, over the consecutive $2 \mathrm{~d}$. Calculated LPS levels per $10^{9}$ organisms were 22-fold (range 3168 -fold) higher than the levels detected in vitro.

\section{Extracellular location of TDP}

Sonication experiments demonstrated 16-fold more (by ELISA) TDP in broth supernatants than in cell-sonicate supernatants of the same broth-grown L. pneumophila (Table 3). The sonication procedure used caused breakage of approximately $50 \%$ of the cells (estimated by electron microscopy) and had no effect on control TDP measured enzymically or as antigen.

\section{Immunoblot detection of TDP}

The polyacrylamide gels were heavily loaded with lung-macerate protein in this study (Fig. $1 a$, lane 2), much of which separated over the same $M_{\mathrm{r}}$ range as TDP (lane 3 ). This high loading of total protein caused distortion of the bands in adjacent tracks of the gel. 
Table 3. Extracellular location of TDP

\begin{tabular}{|c|c|c|c|c|}
\hline \multicolumn{5}{|c|}{ All assays were done in duplicate. ND, Not detected } \\
\hline $\begin{array}{l}\text { Culture } \\
\text { no. }\end{array}$ & $\begin{array}{l}\text { Viable count } \\
\text { (c.f.u. } \mathrm{ml}^{-1} \text { ) }\end{array}$ & Sample & $\begin{array}{l}\text { c.p.u. } \\
\left(\mathrm{ml}^{-1}\right)\end{array}$ & $\begin{array}{l}\text { TDP by ELISA } \\
\left(\mu \mathrm{g} \mathrm{ml}^{-1}\right)\end{array}$ \\
\hline 1 & $8.0 \times 10^{9}$ & $\begin{array}{l}\text { Broth culture supernatant } \\
\text { Cell sonicate supernatant* }\end{array}$ & $\begin{array}{l}320 \\
\mathrm{ND}\end{array}$ & $\begin{array}{l}2 \cdot 22 \\
0 \cdot 19\end{array}$ \\
\hline 2 & $6.0 \times 10^{9}$ & $\begin{array}{l}\text { Broth culture supernatant } \\
\text { Cell sonicate supernatant* }\end{array}$ & $\begin{array}{l}320 \\
\text { ND }\end{array}$ & $\begin{array}{l}2 \cdot 47 \\
0 \cdot 14\end{array}$ \\
\hline 3 & $1.0 \times 10^{10}$ & $\begin{array}{l}\text { Broth culture supernatant } \\
\text { Cell sonicate supernatant* }\end{array}$ & $\begin{array}{l}320 \\
\text { ND }\end{array}$ & $\begin{array}{l}2 \cdot 33 \\
0 \cdot 15\end{array}$ \\
\hline 4 & $5.6 \times 10^{9}$ & $\begin{array}{l}\text { Broth culture supernatant } \\
\text { Cell sonicate supernatant* } \\
\text { Control TDP } \\
\text { Sonicated control TDP }\end{array}$ & $\begin{array}{l}320 \\
\text { ND } \\
320 \\
320\end{array}$ & $\begin{array}{l}2 \cdot 97 \\
0 \cdot 15 \\
2 \cdot 0 \\
2 \cdot 15\end{array}$ \\
\hline
\end{tabular}

* Cells from $10 \mathrm{ml}$ YEB were washed and resuspended in $10 \mathrm{ml}$ PBS before sonication and centrifugation to obtain the supernatant fraction.

The immunoblot technique used in the present study detected as little as $50 \mathrm{ng}$ purified TDP diluted in PBS (Fig. 1b). However, sensitivity was greatly decreased in the presence of lungmacerate supernatant. Sensitivity could be restored by prolonging the incubation of the HRPconjugate-reacted blots with substrate. By this means TDP was detected in macerate supernatants from the lungs of guinea-pigs killed $3 \mathrm{~d}$ after infection (Fig. $1 e$, lanes 3 and 4). ELISA titres, corrected for the effect of macerate (see above), showed that these bands contained 30 and $90 \mathrm{ng}$ TDP, respectively. The bands observed in the lung macerates of infected guinea-pigs appeared skewed compared to control TDP (cf. Fig. la).

\section{DISCUSSION}

TDP purified from culture supernatants of L. pneumophila is known to cause pulmonary lesions in guinea-pigs similar to those observed in experimental and clinical Legionnaires' disease (Baskerville et al., 1986; Conlan et al., 1986). Intranasal administration of as little as $20 \mu \mathrm{g}$ TDP is sufficient to cause death in experimental animals (Baskerville et al., 1986).

The present investigation demonstrated in vivo production of TDP by L. pneumophila in the lungs of experimentally infected guinea-pigs. The levels of TDP detected in supernatants of macerates of guinea-pig lungs $3 \mathrm{~d}$ after infection were of the same order as those known to cause death (Baskerville et al., 1986). Furthermore, the levels of TDP detected in the present in vivo studies represent only the levels of TDP present at the time of killing. It is possible, therefore, that far more TDP was produced during the course of experimental infection than demonstrated herein. Additionally, the efficiency of recovery of TDP from lung macerates is probably low; after maceration and centrifugation a large pellet of lung tissue remained.

Although calculated TDP levels remained relatively constant in the in vivo and the in vitro studies, there was a substantial increase in TDP levels in vivo compared to in vitro, possibly due to induction. However, neither the efficiency of recovery of $L$. pneumophila from the lung macerates nor the turnover of organisms in the lungs during infection are known.

In parallel studies far more LPS was also detected in supernatants of lung-macerates than in culture supernatants. The presence of non-cell-associated LPS in macerate supernatant fractions probably indicates the existence of large numbers of dead, lysed organisms. Whilst sonication experiments suggested that cell lysis released very little TDP, a finding supported by Berdal et al. (1982), the TDP produced by organisms in vivo, when they were viable, could account for the higher levels detected in the lungs of infected animals. The relative contributions of host defence mechanisms, maceration and freezing and thawing of lung tissue to this bacteriolysis are unknown. 


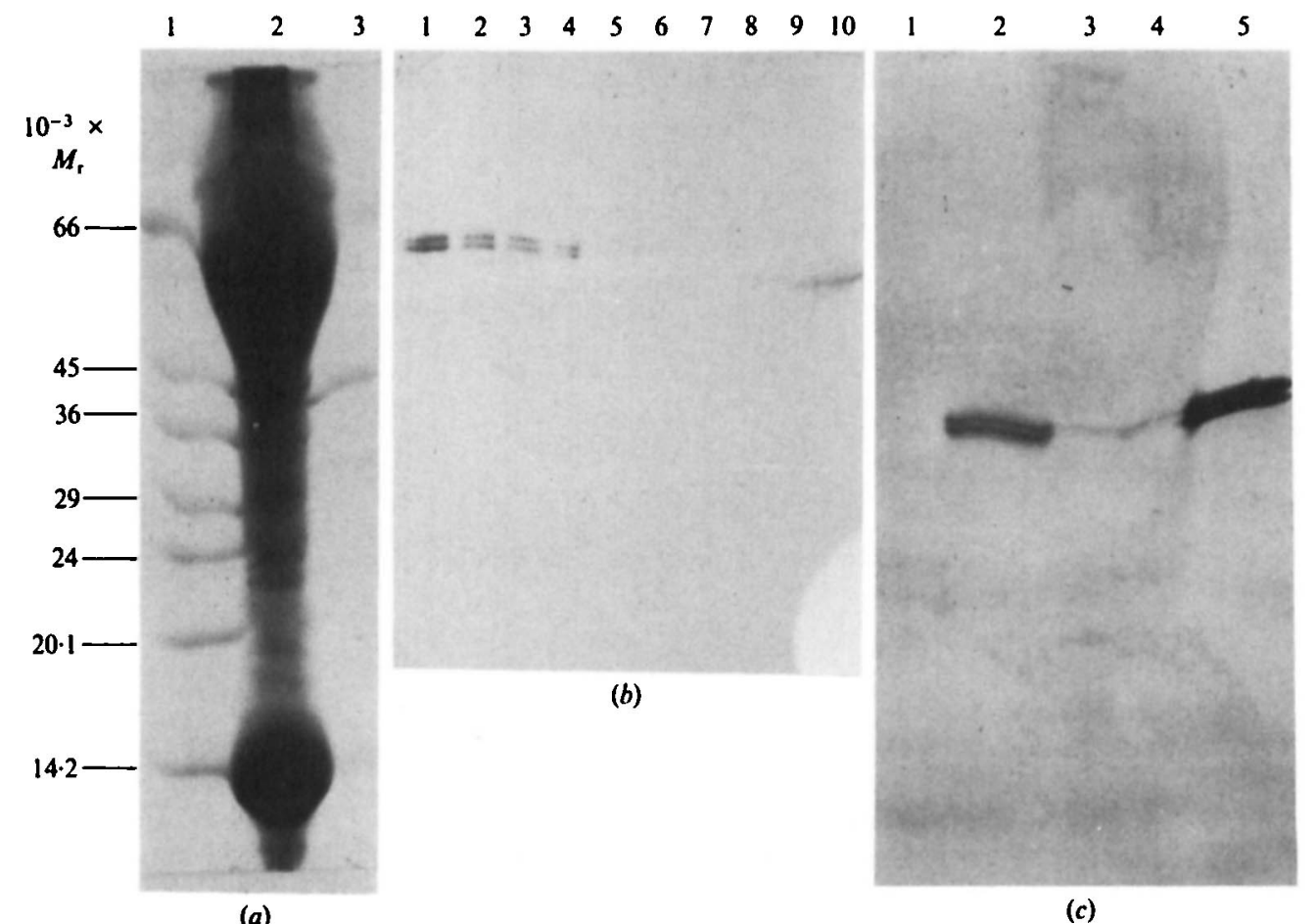

(a)

(c)

Fig. 1. SDS-PAGE and Western immunoblotting for detection of TDP in guinea-pig lung. (a) Separation of lung-macerate supernatant. Lane 1, $M_{\mathrm{r}}$ markers; lane 2, normal lung macerate; lane 3, purified TDP $(5 \mu \mathrm{g})$. (b) Sensitivity of immunoblotting for detection of TDP. Lanes $1-4,500 \mathrm{ng}, 200 \mathrm{ng}$, $100 \mathrm{ng}$ and $50 \mathrm{ng}$, respectively, of purified TDP diluted in PBS; lanes 5 and 6, normal lung-macerate supernatant; lanes $7-10,50 \mathrm{ng}, 100 \mathrm{ng}, 200 \mathrm{ng}$ and $500 \mathrm{ng}$, respectively, of purified TDP diluted in normal lung-macerate supernatant. $(c)$ Immunoblot analysis of lung-macerate supernatants from $3 \mathrm{~d}$ infected guinea-pigs. Lane 1 , normal lung supernatant; lane 2 , normal lung supernatant containing $2 \mu \mathrm{g}$ purified TDP; lanes 3 and 4, lung-macerate supernatant from infected animals (TDP loading $30 \mathrm{ng}$ and $90 \mathrm{ng}$, respectively, by calculation; corrected data); lane 5, $2 \mu \mathrm{g}$ purified TDP.

Lung-macerate supernatant caused a pronounced increase in ELISA titre for TDP (but not for LPS), whereas an opposite effect was observed by immunoblot analysis for TDP. The reasons for this are currently unclear, especially as normal macerate supernatant alone did not react in either assay. Co-transfer of excess lung-macerate protein during electroblotting may interfere with the efficient transfer of TDP. Despite the decrease in sensitivity, TDP was demonstrated in immunoblots of infected lung macerate thus confirming the ELISA findings.

TDP has recently been observed in situ, using immunocytochemical techniques, in the lungs of aerosol-infected animals (Williams et al., 1987). An intimate relationship was demonstrated between the distribution of pulmonary lesions, L. pneumophila cells and TDP. Coupled with the results presented here, these findings indicate an important role for TDP in the pathogenesis of Legionnaires' disease.

Caseinase activity has been demonstrated for other serogroups of $L$. pneumophila and other Legionella spp. (Berdal \& Fossum, 1982; Conlan, 1987). TDP was the only extracellular protease of L. pneumophila with caseinase activity (Conlan et al., 1986). Concentrated culture supernatants of Legionella spp. with high caseinase activity also demonstrated TDP activity (Conlan, 1987). If TDPs from different Legionella spp. prove to be antigenically similar, it may be possible to develop an immunochemical assay for the rapid detection of infections due to all legionellae. This would offer advantages over presently used immunodiagnostic procedures in 
which diagnosis depends upon the use of narrow-range, serogroup-specific reagents. Finally it remains to be shown what effects TDP has on specific host proteins of potential relevance to the pathogenesis of Legionnaires' disease.

This work was funded by an MRC project grant to J. W. Conlan and A. Williams. We thank Dr R. B. Fitzgeorge for aerosol infection of guinea-pigs and Dr A. Baskerville for helpful advice and discussion.

\section{REFERENCES}

Baskerville, A., Fitzgeorge, R. B., Broster, M., Hambleton, P. \& Dennis, P. J. (1981). Experimental transmission of Legionnaires' disease by exposure to aerosols of Legionella pneumophila. Lancet ii, 1389-1390.

Baskerville, A., Conlan, J. W., Ashworth, L. A. E. \& DowseTr, A. B. (1986). Pulmonary damage caused by a protease from Legionella pneumophila. British Journal of Experimental Pathology 67, 527536.

Berdal, B. P. \& Fossum, K. (1982). Caseinate precipitating proteinases from Legionella species: their presence and immunogenicity. European Journal of Clinical Microbiology 1, 7-11.

Berdal, B. P., Olsvik, O., Myhre, S. \& Omland, T. (1982). Demonstration of extracellular chymotrypsin-like activity from various Legionella species. Journal of Clinical Microbiology 16, 452-457.

CONLAN, J. W. (1987). Studies of lipopolysaccharide and extracellular proteases from Legionellae of differing virulence. $\mathrm{PhD}$ thesis, CNAA.

Conlan, J. W. \& Ashworth, L. A. E. (1986). The relationship between the serogroup antigen and lipopolysaccharide of Legionella pneumophila. Journal of Hygiene 96, 39-48.

Conlan, J. W., Baskerville, A. \& Ashworth, L. A. E. (1986). Separation of Legionella pneumophila proteases and purification of a protease which produces lesions like those of Legionnaires' disease in guinea-pig lung. Journal of General Microbiology 132, $1565-1574$.

EDELSTEIN, P. H. (1981). Improved semi-selective medium for isolation of Legionella pneumophila from contaminated clinical and environmental specimens. Journal of Clinical Microbiology 14, 298-303.

Gul'NiK, S. V., Yusupova, M. P., Lavrenova, G. I., Tartakovsky, I. S., Prozorovsky, S. V. \& Stepanov, V. M. (1986). Proteinases of Legionella: phenylalanineaminopeptidase of $L$. pneumophila. Journal of General Microbiology 132, 387-392.
KYHSE-ANDERSEN, J. (1984). Electroblotting of multiple gels: a simple apparatus without buffer tank for rapid transfer of proteins from polyacrylamide to nitrocellulose. Journal of Biochemical and Biophysical Methods 10, 203-209.

LAEMMLI, U. K. (1970). Cleavage of structural proteins during the assembly of the head of bacteriophage $T 4$. Nature, London 227, 680-685.

MÜLLER, H. E. (1980). Proteolytic action of Legionella pneumophila on human serum proteins. Infection and Immunity 27, 51-53.

MÜLLER, H. E. (1981). Enzymatic profile of Legionella pneumophila. Journal of Clinical Microbiology 13, 423-426.

Nakane, P. K. \& Kawaol, A. (1974). Peroxidase labelled antibody. A new method of conjugation. Journal of Histochemistry and Cytochemistry 22, 1084-1091.

NEwELL, D. G. (1987). Identification of the outer membrane proteins of Campylobacter pyloridis and antigenic cross-reactivity between Campylobacter pyloridis and Campylobacter jejuni. Journal of General Microbiology 133, 163-170.

Ristroph, J. D., Hedlund, K. W. \& Allen, R. G. (1980). Liquid medium for the growth of Legionella pneumophila. Journal of Clinical Microbiology 11, 19-21.

Thompson, R., Miller, R. D. \& Iglewski, B. H. (1981). In vitro production of an extracellular protease by Legionella pneumophila. Infection and Immunity 34, 299-302.

Williams, A., Baskerville, A., Dowsett, A. B. \& Conlan, J. W. (1987). Immunocytochemical demonstration of the association between $L$. pneumophila, its tissue-destructive protease and pulmonary lesions in experimental Legionnaires' disease. Journal of Pathology (in the Press). 